\title{
Expression of $\beta$-adrenergic receptors in pediatric malignant brain tumors
}

\author{
IACOPO SARDI ${ }^{1}$, LAURA GIUNTI ${ }^{2}$, CECILIA BRESCI $^{3}$, ANNA MARIA BUCCOLIERO ${ }^{4}$, \\ DUCCIO DEGL'INNOCENTI ${ }^{4}$, STEFANIA CARDELLICCHIO ${ }^{1}$, \\ GIANNA BARONI ${ }^{4}$, FRANCESCA CASTIGLIONE ${ }^{4}$, MARTINA DA ROS ${ }^{1}$, \\ PATRIZIO FIORINI ${ }^{3}$, SABRINA GIGLIO $^{2}$, LORENZO GENITORI $^{5}$, \\ MAURIZIO ARICÒ ${ }^{1}$ and LUCA FILIPPI ${ }^{3}$
}

\author{
${ }^{1}$ Department of Pediatric Hematology-Oncology; ${ }^{2}$ Medical Genetics Unit; ${ }^{3}$ Department of Perinatal Medicine, \\ Meyer Children's Hospital; ${ }^{4}$ Department of Human Pathology and Oncology, Florence University Medical School; \\ ${ }^{5}$ Division of Neurosurgery, Meyer Children's Hospital, Florence, Italy
}

Received February 28, 2012; Accepted September 21, 2012

DOI: $10.3892 / 01.2012 .989$

\begin{abstract}
ARs) are $\mathrm{G}$ protein-coupled receptors that activate signal transduction pathways involved in angiogenesis, resulting in enhanced tumor vascularization and more aggressive growth. In this study, we evaluated the expression of $\beta$-ARs in a population of 12 children affected by malignant primary brain tumors. We found a significant expression of $\beta 1$ - and $\beta 2$-ARs in all 12 samples as well as the 3 cell lines tested (U87MG, T98G and DAOY). The mean absolute $\beta 1$-AR mRNA level standardized to GAPDH was 5.81 (range, -7.91 to 11.29) for brain tumors and 8.59 (range, 6.046 to 12.59) for cell lines (U87MG, DAOY and T98G), respectively. The mean absolute $\beta 2$-AR mRNA level was 4.74 (range, -9.30 to 8.45) for tumor specimens and 7.64 (range, 5.85 to 8.88 ) for cell lines. These real-time quantitative (qRT)-PCR expression data were confirmed by immunohistochemical analysis. Our study evaluated the presence of $\beta 1$ - and $\beta 2$-ARs in malignant pediatric brain tumors and brain tumor cell lines.
\end{abstract}

\section{Introduction}

$\beta$-adrenergic receptors ( $\beta$-ARs) are $\mathrm{G}$ protein-coupled molecules that activate the protein kinase A pathway by

Correspondence to: Dr Iacopo Sardi, Department of Pediatric Hematology-Oncology, Meyer Children's Hospital, Viale Pieraccini, 24, Florence, I-50139, Italy

E-mail: i.sardi@meyer.it

Abbreviations: $\quad \beta$-ARs, $\beta$-adrenergic receptors; GPCRs, G protein-coupled receptors; OS, overall survival; MMP-9, matrix metalloproteinase-9

Key words: $\beta$-adrenergic receptors, medulloblastoma, anaplastic ependymoma, glioblastoma multiforme, brain tumor cell lines accumulation of the secondary messenger cAMP. This signal transduction pathway appears to increase VEGF gene expression, resulting in enhanced tumor vascularization and more aggressive growth. Although within a tumor mass $\beta$-ARs are mainly localized on intra-tumor vessel walls, studies in cell lines show that they are also expressed on the surface of tumor cells (1).

In vitro and in vivo studies have revealed that adrenergic neurotransmitters are involved in the progression and dissemination of several tumor types, including breast (2), colon (3), prostate (4), pancreatic (5) and ovarian carcinomas (6) and melanoma (7). Increased angiogenesis may result from catecholamine-induced VEGF production by tumor cells (8). A recent study revealed that $\beta$-adrenergic signaling may also play a role in the growth and metastatic dissemination in an orthotopic mouse model of breast cancer (9).

Several epidemiological studies have documented a significantly lower risk of cancer development or recurrence in individuals treated with $\beta$-blocking agents (10-17). Propranolol significantly inhibits norepinephrine-induced VEGF and hypoxia-inducible factor (HIF)-1 $\alpha$ expression and angiogenesis in human prostate, breast and hepatocellular cancer cells (18).

In malignant brain tumors, such as medulloblastoma, glioblastoma and anaplastic ependymoma, hypervascularization may result also from an enhancement of the $\beta$-adrenergic signaling pathway. Data on $\beta$-AR expression in brain tumors are conflicting (19-25). To address this issue we examined the expression of $\beta$-ARs in pediatric brain tumors.

\section{Materials and methods}

Patient population and data collection. The population of this study was a subset of pediatric brain tumor patients diagnosed and treated at Meyer Children's Hospital between 2004 and 2010. The study was approved by the Hospital Ethical Committee and informed consent was obtained from the parents/legal guardians of all patients. 
Table I. Clinical characteristics of primary pediatric brain tumors.

\begin{tabular}{|c|c|c|c|c|c|c|c|}
\hline ID/gender & Age & Histology & Surgery & CT (BMT) & RT & OS (months) & Status \\
\hline $\mathrm{MB} 1 / \mathrm{M}$ & 2 months & Medulloblastoma & GTR & $+(+\mathrm{BMT})$ & + & 10 & DOD \\
\hline $\mathrm{MB} 2 / \mathrm{F}$ & 3 months & Medulloblastoma & GTR & $+(+\mathrm{BMT})$ & - & 49 & NED \\
\hline $\mathrm{MB} 3 / \mathrm{M}$ & 3 years & Medulloblastoma & GTR & $+(+\mathrm{BMT})$ & + & 54 & NED \\
\hline $\mathrm{MB} 4 / \mathrm{F}$ & 8 years & Medulloblastoma & GTR & + & + & 41 & NED \\
\hline $\mathrm{MB} 5 / \mathrm{F}$ & 1 years & Medulloblastoma & GTR & $+(+\mathrm{BMT})$ & - & 35 & NED \\
\hline $\mathrm{EP} 1 / \mathrm{F}$ & 9 years & Anaplastic ependymoma & PTR & + & + & 44 & DOD \\
\hline $\mathrm{EP} 2 / \mathrm{F}$ & 3 years & Anaplastic ependymoma & GTR & + & + & 55 & NED \\
\hline $\mathrm{EP} 3 / \mathrm{F}$ & 10 years & Anaplastic ependymoma & GTR & + & + & 43 & NED \\
\hline $\mathrm{EP} 4 / \mathrm{M}$ & 15 years & Anaplastic ependymoma & PTR & - & + & 14 & DOD \\
\hline EP5/M & 5 years & Anaplastic ependymoma & GTR & + & + & 42 & NED \\
\hline GBM1/F & 8 years & Glioblastoma multiforme & PTR & + & + & 27 & DOD \\
\hline GBM2/M & 9 years & Glioblastoma multiforme & PTR & + & + & 12 & DOD \\
\hline
\end{tabular}

RT, radiotherapy; CT, chemotherapy; GTR, gross total removal; PTR, partial total removal; BMT, bone marrow transplantation; DOD, died of disease; NED, no evidence of disease.

We studied 12 primary malignant brain tumors of the following types: medulloblastoma (WHO grade IV, $\mathrm{n}=5$ ), anaplastic ependymoma (WHO grade III, n=5) and glioblastoma multiforme (WHO grade IV, $\mathrm{n}=2$ ).

Mean overall survival (OS) for the twelve patients was 35.5 months (range, 10-55 months); at the end of the study seven $(58 \%)$ were alive while 5 had succumbed to progressive disease. Eight patients were treated with complete/gross tumor resection followed by chemotherapy and/or radiotherapy, while the remaining 4 medulloblastoma patients received high-dose, myeloablative chemotherapy with autologous stem cell rescue. Ten of the 12 patients received radiotherapy.

The main clinical characteristics of the patients are summarized in Table I.

Cell lines and RNA isolation. The human cell lines DAOY (medulloblastoma), T98G (glioblastoma multiforme) and U87MG (glioblastoma-astrocytoma) were cultured in medium (Eagle's MEM with Earle's Balanced Salts; MEM EBSS) supplemented with $10 \%$ fetal bovine serum (FBS), $1 \%$ L-glutamine, $1 \mathrm{mM}$ Na pyruvate, $0.1 \mathrm{mM}$ non-essential amino acids and $1 \%$ penicillin/streptomycin antibiotics at $37^{\circ} \mathrm{C}$ in a humidified $5 \% \mathrm{CO}_{2}$ atmosphere. All media were purchased from Euroclone (Devon, UK).

RNA of tumors and cell lines was extracted using a QIAamp RNA Blood Mini kit (Qiagen, Santa Clarita, CA, USA) and quantified using a NanoDrop 2000 spectrophotometer (Thermo Scientific, Logan, UT, USA). The RNA fragmentation state was evaluated by $1.5 \%$ agarose gel electrophoresis.

Real-time quantitative ( $q R T)$ - PCR. All RNA samples (500 ng) were reverse transcribed to cDNA using SuperScript ${ }^{\mathrm{TM}}$ First-Strand Synthesis System (Invitrogen, Carlsbad, CA, USA) according to the manufacturer's instructions.

TaqMan real-time quantitative PCR was performed on an ABI PRISM 7000 Sequence Detector System (Applied Biosystems, Foster City, CA, USA).
PCR products for $\beta 1, \beta 2$ and $\beta 3$-AR genes were detected using gene-specific primers and probes labeled with the reporter dye FAM (Applied Biosystems). The GAPDH (glyceraldehyde-3-phosphate dehydrogenase) gene was used as an endogenous control gene for normalization and was detected using gene-specific primers and probes labeled with the reporter dye VIC (Applied Biosystems).

PCR was carried out in triplicate on a 96-well plate with $20 \mu \mathrm{l}$ per well, using 1X TaqMan Universal PCR Master mix. After incubation for $2 \mathrm{~min}$ at $50^{\circ} \mathrm{C}$ and $10 \mathrm{~min}$ at $95^{\circ} \mathrm{C}$, the reaction continued for 50 cycles of $95^{\circ} \mathrm{C}$ for $15 \mathrm{sec}$ and $60^{\circ} \mathrm{C}$ for $1 \mathrm{~min}$. The results were evaluated using the ABI 7000 PRISM software and the $\mathrm{Ct}$ values were exported to Microsoft Excel.

The $2^{-\Delta \Delta C t}$ method described by Livak and Schmittgen (26) was used to analyse the results. The $\mathrm{Ct}$ values for each set of three reactions were averaged for all subsequent calculations. For each tumor sample the universal human reference RNA (Stratagene, Santa Clara, CA, USA) was used as a control sample. Significance was estimated according to the values in general use $(\mathrm{P}<0.05)$.

Immunohistochemistry. Surgical specimens were routinely formalin fixed and paraffin embedded. Histological sections were stained with hematoxylin-eosin (H\&E) for histomorphological evaluation. Sections (5 $\mu \mathrm{m}$ thick) of the most representative sample from each tumor were mounted on electrostatic slides and used for immunohistochemical staining. Immunohistochemical studies were performed using the standard streptavidin-biotin technique and commercially available reagents: rabbit polyclonal antibody anti-adrenoceptor, $\beta-1$ (1:30 dilution; Santa Cruz Biotechnology, Inc., Santa Cruz, CA, USA); rabbit polyclonal antibody anti-adrenoceptor, $\beta-2$ (1:100 dilution; Chemicon, Temecula, CA, USA). A positive control was normal skin. A negative control was performed by substituting the primary antibody with a non-immune serum at the same concentration. The control sections were treated in parallel with the samples. 


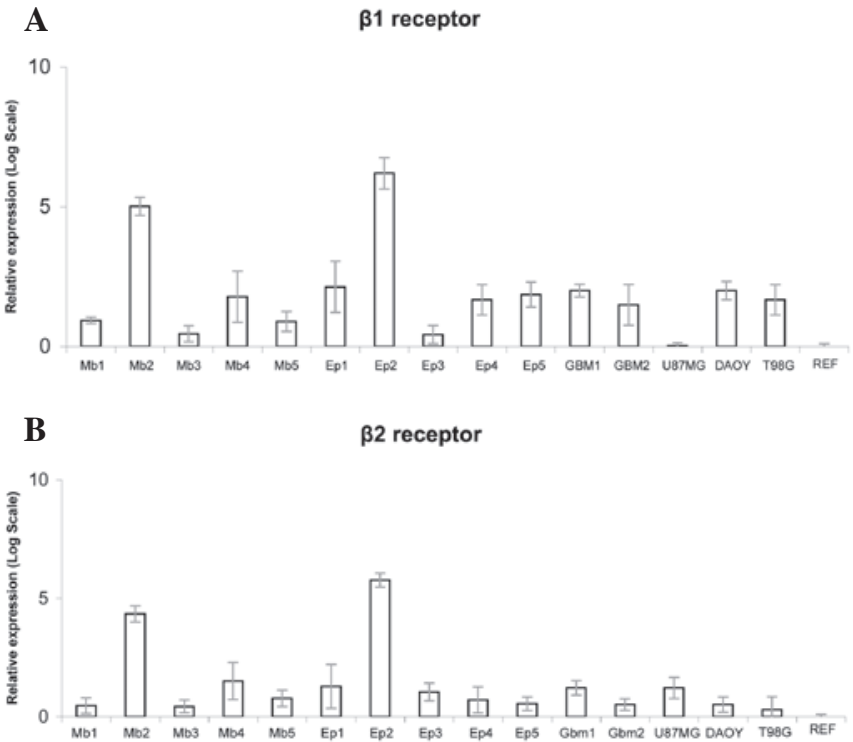

Figure 1. (A) $\beta 1-A R$ and (B) $\beta 2-A R$ relative expression (mean values from three replicates) calculated as $2^{-\Delta \Delta C t}$. MB, medulloblastoma; EP, ependymoma; GBM, glioblastoma multiforme. Ref, universal human reference RNA (Stratagene); U87MG, glioblastoma-astrocytoma; DAOY, medulloblastoma; T98G, glioblastoma multiforme.

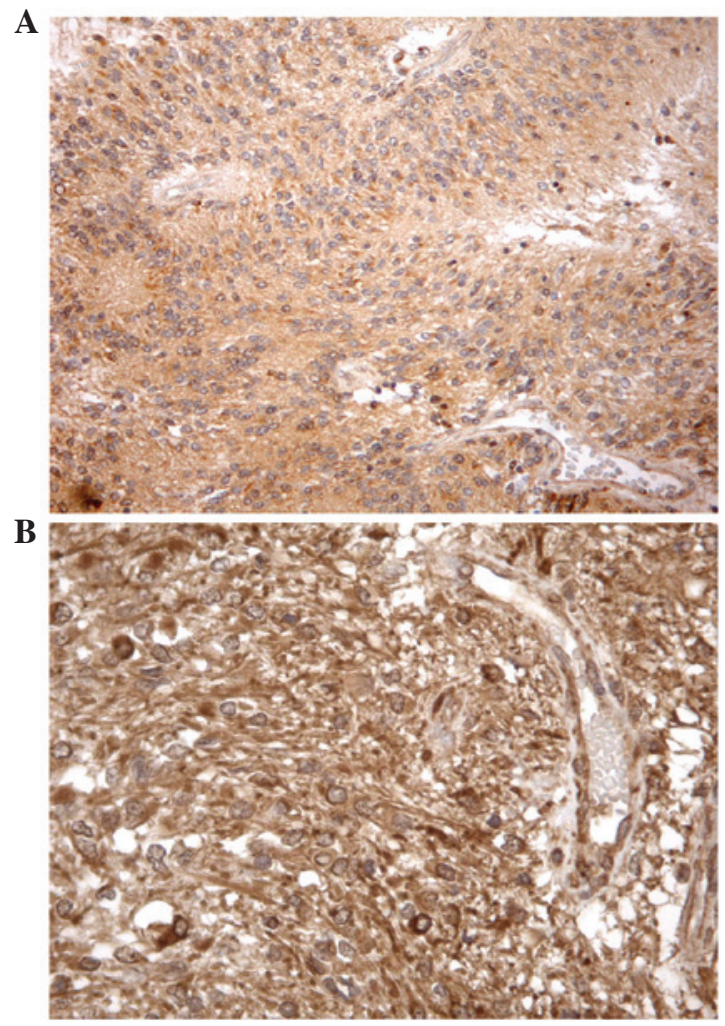

Figure 2. Immunohistochemical stain for (A) $\beta 1-A R$ in anaplastic ependymoma samples and (B) $\beta 2$-AR in glioblastoma samples. A mainly cytoplasmic immunostaining was observed in almost the entirety of the tumor and endothelial cells; original magnification (A) x200, (B) x400.

Immunohistochemical results were categorized using a 3 -grade score: $0(<10 \%$ positive tumor cells); 1 (10 to $49 \%$ positive tumor cells); 2 ( $>50 \%$ positive tumor cells). In addition, the immunostaining was also evaluated with regard to its intensity: weak and strong.
Table II. $\beta 1$ and $\beta 2$-AR analysis in pediatric brain tumors.

\begin{tabular}{|c|c|c|c|c|}
\hline \multirow[b]{2}{*}{ Sample } & \multicolumn{2}{|c|}{$\begin{array}{c}\text { mRNA expression } \\
\text { levels }(\Delta \Delta \mathrm{Ct})\end{array}$} & \multicolumn{2}{|c|}{ Immunohistochemistry } \\
\hline & $\beta 1$ receptor & $\beta 2$ receptor & - $\beta 1$ receptor & $\beta 2$ receptor \\
\hline MB 1 & 9.598 & 8.345 & 2 & 2 \\
\hline MB2 & -3.968 & -4.528 & 1 & 2 \\
\hline MB3 & 11.193 & 8.451 & 2 & 2 \\
\hline MB4 & 6.785 & 4.891 & 1 & 2 \\
\hline MB5 & 9.721 & 7.293 & 2 & 2 \\
\hline EP1 & 5.611 & 5.637 & 2 & 2 \\
\hline EP2 & -7.911 & -9.264 & 1 & 2 \\
\hline EP3 & 11.291 & 6.421 & 1 & 2 \\
\hline EP4 & 7.141 & 7.551 & 1 & 2 \\
\hline EP5 & 6.525 & 8.061 & 2 & 2 \\
\hline GBM1 & 6.046 & 5.846 & 1 & 2 \\
\hline GBM2 & 7.751 & 8.180 & 2 & 2 \\
\hline U87MG & 12.59 & 5.846 & & \\
\hline DAOY & 6.046 & 8.18 & & \\
\hline T98G & 7.141 & 8.88 & & \\
\hline Human ref. & 12.698 & 9.887 & & \\
\hline
\end{tabular}

$\beta 1$ and $\beta 2$ mRNA expression in tumor samples standardized to GAPDH (mean values from three replicates). MB, medulloblastoma; EP, ependymoma; GBM, glioblastoma multiforme. Human ref, universal human reference RNA (Stratagene); U87MG, glioblastoma-astrocytoma; DAOY, medulloblastoma; T98G, glioblastoma multiforme. Immunohistochemistry score: $0, \leq 10 \% ; 1,>10 \%$ and $<50 \% ; 2,>50 \%$ positive tumor cells.

\section{Results}

All 12 human brain tumor tissue samples and the three tested cell lines (U87MG, T98G and DAOY) exhibited expression of $\beta 1$ - and $\beta 2$-ARs.

$\beta 1$-AR expression was detected in all 12 tumor samples and in the T98G and DAOY cell lines (Fig. 1A). 32 -AR expression was detected in all 12 tumor samples and in U87MG, T98G and DAOY cells (Fig. 1B). None of the tumor samples expressed $\beta 3$-AR, nor did the three cell lines or the universal human reference RNA (Stratagene).

The mean absolute $\beta 1-\mathrm{AR}$ mRNA level standardized to GAPDH was 5.81 (range, -7.91 to 11.29) for tumors and 8.50 (range, 6.046 to 12.59) for cell lines (U87MG, DAOY and T98G). The median absolute $\beta 2$-AR mRNA level standardized for GAPDH was 4.74 (range, -9.30 to 8.45 ) for tumor specimens and 7.62 (range, 5.85 to 8.88 ) for cell lines. Human reference mRNA showed a value of 12.698 for $\beta 1$-AR and 9.887 for $\beta 2$-AR. Values of $\beta 1$ - and $\beta 2-A R$ mRNA levels are shown in Table II.

All brain tumor samples had a score of 2 at $\beta 2$-AR immunohistochemistry analysis. In immunohistochemistry for $\beta 1$-AR, 6 tumors had a score of 2 and 6 had score 1 , while none was $\beta 1$-AR-negative. Positive staining for $\beta 1$-AR was observed in tissues from 3 medulloblastoma, 2 anaplastic ependymoma and only 1 glioblastoma. Positive immunostaining was usually 
confined to the cytoplasm of both the tumor cells (when present) and the endothelial cells (which stained positively in all the cases studied; Fig. 2).

\section{Discussion}

$\beta$-ARs are G protein coupled receptors (GPCRs) that initiate the adenylyl cyclase/cAMP/PKA/CREB pathway which interacts with the EGFR and Src/STAT pathways as well as the arachidonic acid cascade (8). These signal transduction pathways are positive regulators of tumor development and progression and may therefore represent a possible novel target for treatment.

In the present study we evaluated the expression of $\beta$-ARs in malignant primary brain tumors of children. This issue has been considered controversial due to conflicting results. The absence of $\beta$-AR in capillaries isolated from glial tumors has been demonstrated (19). Subsequently, rat astroglial and neuronal cell lines have been shown to express $\beta$-AR on their surface (20).

Our study population included highly vascularized brain tumors, such as glioblastoma multiforme, anaplastic ependymoma and medulloblastoma. Our findings demonstrate by qRT-PCR and immunohistochemistry that $\beta 2$-AR was overexpressed in all tumors, whereas overexpression of $\beta 1-\mathrm{AR}$ was found in 6 of 12 patients. There was no correlation between $\beta$-AR expression and the presenting features of the patient or histological pattern of the tumor.

$\beta$-ARs are known to have a widespread distribution in numerous tissues and cell lines. We have been particularly interested in $\beta$-AR located on blood vessels: possible targets include endothelial cells, adventitial cells, pericytes, fibroblasts, macrophages, adipocytes, perivascular axons and Schwann cells. Autoradiography methods have demonstrated the presence of both $\beta 1$ and $\beta 2$ antagonist binding sites in all three layers of blood vessel walls (1).

Preclinical studies suggest that the $\beta$-adrenergic system affects tumor progression by promoting proangiogenic factors $(18,27)$ and propranolol shows an inhibitory effect on cancer cell proliferation (28) or appears to potentiate the efficacy of antineoplastic drugs (29). These observations, together with the evidence that metastasis (migration of tumor cells via blood or lymphatic vessels from the primary tumor site) is strictly regulated by exogenous cell signaling molecules, including ligands of GPCRs $(30,31)$ may speculate a correlation between cancer and GPCRs/GPCR ligands, including $\beta$-blockers.

A number of previous clinical observations or laboratory models have studied the role of $\beta$-ARs in cancer pathophysiology and the possibility of influencing cancer-specific survival by pharmacological targeting of $\beta$-AR. Due to the wide use/intake of propanolol and propanolol-derived drugs, a number of epidemiological and observational studies about clinical features of patients treated with $\beta$-blocking agents are now available, including studies revealing an unexpected preventive effect of primary cancer occurrence in patients receiving $\beta$-blockers $(10-14,16,32)$.

The mechanism by which propranolol reduces tumor recurrence rates is not completely understood, but may relate to its capacity to impair metastases formation which involves migration of malignant cells from the primary tumor via lymphatic routes or blood vessels. This process is tightly regulated by exogenous signaling molecules $(30,31)$. Cell migration has been demonstrated to be mediated by $\beta$-ARs and this process is inhibited by propranolol $(3,4)$. In vitro $\beta$-adrenergic stimulation compromises NK cell activity and resistance to tumor metastasis in rats, while propranolol appears to block this phenomenon (33). Brain tumor secretion of matrix metalloproteinase-9 (MMP-9), a protein which favors the dissemination of glioma tumoral cells by disruption of the blood-brain barrier, is abrogated by pharmacological targeting $\beta$-AR with propanolol $(24,34)$.

One promising hypothesis is that the $\beta$-adrenergic system plays an important role in the promotion of angiogenesis that may be counteracted by propranolol $(18,27)$.

Notably, in a mouse model of proliferative retinopathy, the pharmacological blockade of $\beta$-AR with propranolol has been demonstrated to reduce retinal levels of HIF-1 $\alpha$ and, consequently, of proangiogenic factors (VEGF and IGF-1), markedly reducing retinal neoangiogenesis (35).

In conclusion, data from a small number of previous studies indicate that $\beta$-blockers may have a role as novel therapeutic agents in reducing tumor metastasis, tumor recurrence and cancer-specific mortality. Although further studies are needed to better define $\beta$-AR expression in pediatric CNS tumors, a possible effect of propranolol and other $\beta$-blockers on the natural history is conceivable. The demonstration of the presence of $\beta$-ARs on pediatric malignant brain tumors may be the basis for an experimental clinical use of propranolol.

\section{Acknowledgements}

This study was supported by Associazione Italiana per la Ricerca sul Cancro (AIRC), grant RG-6232; 'Amicodivalerio' Onlus; 'NOI PER VOI' Onlus; Fondazione Tommasino Bacciotti; Fondazione Anna Meyer.

\section{References}

1. Daly CJ and McGrath JC: Previously unsuspected widespread cellular and tissue distribution of $\beta$-adrenoceptors and its relevance to drug action. Trends Pharmacol Sci 32: 219-226, 2011.

2. Drell TL IV, Joseph J, Lang K, Niggemann B, Zaenker KS and Entschladen F: Effects of neurotransmitters on the chemokinesis and chemotaxis of MDA-MB-468 human breast carcinoma cells. Breast Cancer Res Treat 80: 63-70, 2003.

3. Masur K, Niggemann B, Zanker KS and Entschladen F: Norepinephrine-induced migration of SW 480 colon carcinoma cells is inhibited by beta-blockers. Cancer Res 61: 2866-2869, 2001.

4. Palm D, Lang K, Niggemann B, Drell TL IV, Masur K, Zaenker KS and Entschladen F: The norepinephrine-driven metastasis development of PC-3 human prostate cancer cells in $\mathrm{BALB} / \mathrm{c}$ nude mice is inhibited by beta-blockers. Int J Cancer 118: 2744-2749, 2006

5. Al-Wadei HA, Al-Wadei MH and Schuller HM: Prevention of pancreatic cancer by the beta-blocker propranolol. Anticancer Drugs 20: 477-482, 2009.

6. Sood AK, Bhatty R, Kamat AA, et al: Stress hormone-mediated invasion of ovarian cancer cells. Clin Cancer Res 12: 369-375, 2006.

7. Yang EV, Kim SJ, Donovan EL, et al: Norepinephrine upregulates VEGF, IL-8, and IL-6 expression in human melanoma tumor cell lines: implications for stress-related enhancement of tumor progression. Brain Behav Immun 23: 267-275, 2009.

8. Schuller HM: Is cancer triggered by altered signalling of nicotinic acetylcholine receptors? Nat Rev Cancer 9: 195-205, 2009. 
9. Sloan EK, Priceman SJ, Cox BF, et al: The sympathetic nervous system induces a metastatic switch in primary breast cancer. Cancer Res 70: 7042-7052, 2010.

10. Algazi M, Plu-Bureau G, Flahault A, Dondon MG and Lê MG: Could treatments with beta-blockers be associated with a reduction in cancer risk? Rev Epidemiol Sante Publique 52: 53-65, 2004 (In French).

11. Perron L, Bairati I, Harel F and Meyer F: Antihypertensive drug use and the risk of prostate cancer (Canada). Cancer Causes Control 15: 535-541, 2004.

12. Powe DG, Voss MJ, Zänker KS, Habashy HO, Green AR, Ellis IO and Entschladen F: Beta-blocker drug therapy reduces secondary cancer formation in breast cancer and improves cancer specific survival. Oncotarget 1: 628-638, 2010.

13. Ganz PA, Habel LA, Weltzien EK, Caan BJ and Cole SW: Examining the influence of beta blockers and ACE inhibitors on the risk for breast cancer recurrence: results from the LACE cohort. Breast Cancer Res Treat 129: 546-556, 2011.

14. Barron TI, Connolly RM, Sharp L, Bennett K and Visvanathan $\mathrm{K}$ : Beta blockers and breast cancer mortality: a population-based study. J Clin Oncol 29: 2635-2644, 2011.

15. Melhem-Bertrandt A, Chavez-Macgregor M, Lei X, et al: Betablocker use is associated with improved relapse-free survival in patients with triple-negative breast cancer. J Clin Oncol 29: 2645-2652, 2011

16. De Giorgi V, Grazzini M, Gandini S, Benemei S, Lotti T, Marchionni N and Geppetti P: Treatment with $\beta$-blockers and reduced disease progression in patients with thick melanoma. Arch Intern Med 171: 779-781, 2011

17. Lemeshow S, Sørensen HT, Phillips G, et al: $\beta$-Blockers and survival among Danish patients with malignant melanoma: a population-based cohort study. Cancer Epidemiol Biomarkers Prev 20: 2273-2279, 2011

18. Park SY, Kang JH, Jeong KJ, et al: Norepinephrine induces VEGF expression and angiogenesis by a hypoxia-inducible factor- $1 \alpha$ protein-dependent mechanism. Int J Cancer 128 2306-2316, 2011

19. Magnoni MS, Frattola L, Piolti R, Govoni S, Kobayashi H and Trabucchi M: Glial brain tumors lack microvascular adrenergic receptors. Eur Neurol 28: 27-29, 1988

20. Ruck A, Millns P, Kendall DA and Hill SJ: Expression of beta 2-adrenoceptors mediating cyclic AMP accumulation in astroglial and neuronal cell lines derived from the rat CNS Biochem Pharmacol 40: 2371-2375, 1990.

21. Sokołowska P and Nowak JZ: Constitutive activity of betaadrenergic receptors in C6 glioma cells. Pharmacol Rep 57: 659-663, 2005.
22. Lung HL, Shan SW, Tsang D and Leung KN: Tumor necrosis factor-alpha mediates the proliferation of rat C6 glioma cells via beta-adrenergic receptors. J Neuroimmunol 166: 102-112, 2005.

23. Annabi B, Lachambre MP, Plouffe K, Moumdjian R and Béliveau R: Propranolol adrenergic blockade inhibits human brain endothelial cells tubulogenesis and matrix metalloproteinase-9 secretion. Pharmacol Res 60: 438-445, 2009.

24. Annabi B, Vaillancourt-Jean E, Weil AG and Béliveau R: Pharmacological targeting of $\beta$-adrenergic receptor functions abrogates NF- $\mathrm{B}$ signaling and MMP-9 secretion in medulloblastoma cells. Onco Targets Ther 3: 219-226, 2010.

25. Toll L, Jimenez L, Waleh N, et al: $\{$ Beta\}2-adrenergic receptor agonists inhibit the proliferation of $1321 \mathrm{~N} 1$ astrocytoma cells. J Pharmacol Exp Ther 336: 524-532, 2011.

26. Livak KJ and Schmittgen TD: Analysis of relative gene expression data using real-time quantitative PCR and the 2(-Delta Delta C(T)) Method. Methods 25: 402-408, 2001

27. Chakroborty D, Sarkar C, Basu B, Dasgupta PS and Basu S: Catecholamines regulate tumor angiogenesis. Cancer Res 69: 3727-3730, 2009.

28. Zhang D, Ma Q, Shen S and Hu H: Inhibition of pancreatic cancer cell proliferation by propranolol occurs through apoptosis induction: the study of beta-adrenoceptor antagonist's anticancer effect in pancreatic cancer cell. Pancreas 38: 94-100, 2009.

29. Pasquier E, Ciccolini J, Carre M, et al: Propranolol potentiates the anti-angiogenic effects and anti-tumor efficacy of chemotherapy agents: implication in breast cancer treatment. Oncotarget 2: 797-809, 2011.

30. Entschladen F, Drell TL IV, Lang K, Joseph J and Zaenker KS Tumour-cell migration, invasion, and metastasis: navigation by neurotransmitters. Lancet Oncol 5: 254-258, 2004.

31. Entschladen F, Drell TL IV, Lang K, Joseph J and Zaenker KS: Neurotransmitters and chemokines regulate tumor cell migration: potential for a new pharmacological approach to inhibit invasion and metastasis development. Curr Pharm Des 11: 403-411, 2005

32. Diaz E, Karlan B, Cass I, Walsh C and Li A: Impact of beta blockers on epithelial ovarian cancer survival. Gynecol Oncol 120 (Suppl 1): S36, 2011.

33. Shakhar G and Ben-Eliyahu S: In vivo beta-adrenergic stimulation suppresses natural killer activity and compromises resistance to tumor metastasis in rats. J Immunol 160: 3251-3258, 1998.

34. Lakka SS, Gondi CS and Rao JS: Proteases and glioma angiogenesis. Brain Pathol 15: 327-341, 2005.

35. Ristori C, Filippi L, Dal Monte M, et al: Role of the adrenergic system in a mouse model of oxygen-induced retinopathy: antiangiogenic effects of beta-adrenoreceptor blockade. Invest Ophthalmol Vis Sci 52: 155-170, 2011. 